\title{
Graphene Quantum Dots Open Up New Prospects for Interfacial Modifying in Graphene/Silicon Schottky Barrier Solar Cell
}

\author{
Chao Geng, ${ }^{1}$ Xiuhua Chen, ${ }^{2}$ Shaoyuan Li ${ }^{1,3}$ Zhao Ding, ${ }^{4}$ Wenhui Ma, ${ }^{1}$ Jiajia Qiu, ${ }^{1}$ \\ Qidi Wang, ${ }^{1}$ Chang Yan $\mathbb{1}^{3},{ }^{3}$ and Hua-jun Fan ${ }^{5}$ \\ ${ }^{1}$ Institute of New Energy/State Key Laboratory of Complex Nonferrous Metal Resources Clean Utilization, Kunming University of \\ Science and Technology, Kunming 650093, China \\ ${ }^{2}$ School of Materials Science and Engineering, Yunnan University, Kunming 650091, China \\ ${ }^{3}$ Australian Centre for Advanced Photovoltaics, School of Photovoltaic and Renewable Energy Engineering, University of New \\ South Wales, Sydney 2052, Australia \\ ${ }^{4}$ Department of Mechanical, Materials and Aerospace Engineering, Illinois Institute of Technology, Chicago 60616, USA \\ ${ }^{5}$ College of Chemical Engineering, Sichuan University of Science and Engineering, Zigong, Sichuan 643000, China
}

Correspondence should be addressed to Shaoyuan Li; 1sy415808550@163.com

Received 23 July 2020; Accepted 30 October 2020; Published 12 February 2021

Copyright (c) 2021 Chao Geng et al. Exclusive Licensee Beijing Institute of Technology Press. Distributed under a Creative Commons Attribution License (CC BY 4.0).

\begin{abstract}
Graphene/silicon $(\mathrm{Gr} / \mathrm{Si})$ Schottky barrier solar cells (SBSCs) are attractive for harvesting solar energy and have been gaining grounds for its low-cost solution-processing. The interfacial barrier between graphene and silicon facilitates the reducing excessive carrier recombination while accelerating the separation processes of photo-generated carriers at the interface, which empowers the performance of $\mathrm{Gr} / \mathrm{Si}$ SBSCs. However, the difficulty to control the interface thickness prevents its application. Here, we introduce the graphene oxide quantum dots (GOQDs) as a unique interfacial modulation species with tunable thickness by controlling the GOQDs particle size. The power conversion efficiency (PCE) of $13.67 \%$ for Gr/Si-based SBSC with outstanding stability in the air is obtained with the optimal barrier thickness $(26 \mathrm{~nm})$ and particle size (4.15 nm) of GOQDs. The GOQDs in Gr/Si-based SBSCs provide the extra band bending which further enhances the PCE for its photovoltaic applications.
\end{abstract}

\section{Introduction}

The global energy transformation has been driven by alarming climate change and global economic growth needs, which demands a greater need for renewable energy and energy efficiency [1]. Nature-rich silicon, as well as carbon, has been attracting attention for its application in the cost-effective energy harvest devices [2]. Transferring graphene, which has a superior optical transmittance as well as electrical conductivity, onto a silicon substrate will make a simple Schottky junction solar cell $[3,4]$. Enormous interests are drawn to study this graphene/silicon heterojunction solar cell because this $2 \mathrm{D}$ graphene has higher carrier mobility, more excellent thermal stability, and the broader optical absorption $[5,6]$.

$\mathrm{Gr} / \mathrm{Si}$ heterojunction SBSCs was first fabricated with power conversion efficiency (PCE) of $1.5 \%$ at room temperature by Wu et al. in 2010 [7]. Graphene in SBSCs served triple roles as (i) a transparent electrode, (ii) a p-type semiconduc- tor forming a Schottky junction with a silicon substrate, and (iii) creating a built-in electric field at graphene-silicon interface to separate photo-generated carriers and collect holes $[7,8]$. The key to improving the PCE performance of $\mathrm{Gr} / \mathrm{Si}$ SBSCs lies in the carrier's ability to have efficient directional movement and the separation of carriers, which are influenced by the work function. Several materials such as $\mathrm{SiO}_{x}$ (native silicon oxide) [9], graphene oxide (GO) [10], aluminum oxide $\left(\mathrm{Al}_{2} \mathrm{O}_{3}\right)$ [11], quantum dots (QDs) [12, 13], conductive polymer (P3HT) [14], fluorine-based graphene (FG) [15], and boron nitride (h-BN) [16] have been studied for the interface modification of the $\mathrm{Gr} / \mathrm{Si}$ SBSCs to suppress the surface recombination process and enhance the tunneling processes for carriers. These modifications generally result in growth to open-circuit voltage $\left(V_{\text {oc }}\right)$ and lead to an increase in the performance of the Gr/Si-based SBSCs. However, these studies demonstrated that the thickness of most modification materials must be $\sim 2 \mathrm{~nm}$ or less to have 
decent PCE efficiency. This is because of the insulating nature of a convention metal-insulator-semiconductor (MIS) structure. Either thinner or thicker barriers could give rise to a serious degradation for performance, as well as an increase in the complexity of Gr/Si SBSCs fabrication and driving the higher fabrication cost. On the other hand, the graphene has a relatively weak work function $\left(W_{g}\right)$ with a low barrier height $(\sim 0.1 \mathrm{eV})$, compared with the conventional silicon $\mathrm{p}-\mathrm{n}$ junction device for high junction barrier $(\sim 0.6-0.7 \mathrm{eV})$ $[17,18]$. As such, this graphene-based device has a low $V_{\text {oc }}$ $(\sim 0.5 \mathrm{~V})$, compared with that of the conventional silicon devices $(0.6-0.7 \mathrm{~V})[19,20]$. To tune the work function of graphene, various materials such as polymers [21, 22], Au nanoparticles [23], Ag nanoparticles [24], Pt cubic nanoparticles $[25]$, and others $[26,27]$ have been employed by p-type doping on graphene. Besides, antireflection coating by $\mathrm{TiO}_{2}$ nanoparticles $\left(\mathrm{TiO}_{2}-\mathrm{NP}\right)$ was employed to increase the device's ability to boost the light trapping of the Gr/Si SBSCs [28]. The higher cost and technical difficulties prevent the wider application of the $\mathrm{Gr} / \mathrm{Si}$-based SBSCs. Fortunately, the efficiency of $\mathrm{Gr} / \mathrm{Si}$-based SBSCs has been caught up with most commercial silicon-based solar cells $(\sim 15 \%)$ less than ten years $[9,29]$ although still slightly behind the peak efficiency of MIS inversion layer solar cells ( 20\%) in the laboratory.

In this study, graphene oxide quantum dots (GOQDs) as a high-quality interfacial barrier are introduced for modifying interface properties of the Schottky junction in Gr/Si-based SBSCs. The investigation will focus on the relationship between PCE and the particle size and thickness of GOQDs. The GOQDs will be characterized by FourierTransform Infrared (FTIR), X-ray Photoelectron Spectroscopy (XPS), Transmission Electron Microscopy (TEM), Fluorescence spectrometer, and UV-vis spectrophotometer, and its photovoltaic properties will be characterized by Newport 91160 solar simulator. This research will pave a new way for devising as well as optimizing a more economical SBSCs application, especially a thicker interlayer in the MIS inversion model that can be beneficial for the processing techniques in low-cost semiconductor integrated devices in the near future.

\section{Materials and Methods}

2.1. Preparation of GOQDs and $\mathrm{TiO}_{2}$ Nanoparticles. GOQDs were synthesized via direct pyrolyzing citric acid (CA) under hydrothermal treatment with carbonizing, following the literature procedure with some modification [30]. Briefly, $2 \mathrm{~g}$ CA was put into a $30 \mathrm{~mL}$ beaker and heated to 200, 225, and $250^{\circ} \mathrm{C}$, respectively, for $15 \mathrm{~min}$ at each temperature. The color of the liquid form of CA changed from achromatic color to light yellow and finally to orange 30 minutes later, signifying GOQDs have been formed. The orange solution as quasi-GOQDs was dialyzed and soaked in DI water for $48 \mathrm{~h}$ to remove the excess CA and impurities, followed by centrifugation at $10000 \mathrm{rpm}$ (revolutions per minute) several times to detach any agglomerates. The supernatant was eventually conserved for subsequent characterization and film preparation to $\mathrm{Gr} / \mathrm{Si}$-based SBSCs, as described below.
To synthesize the nano- $\mathrm{TiO}_{2}$ colloid, a hydrolysate solution of $1.5 \mathrm{~mL}$ deionized water, $12 \mathrm{~mL}$ ethanol, and $1.5 \mathrm{~mL}$ $\mathrm{HNO}_{3}(0.1 \mathrm{~mol} / \mathrm{L})$ was added at a rate of $0.5 \mathrm{~mL} / \mathrm{min}$ to a precursor solution of $5 \mathrm{~mL}$ of $\mathrm{Ti}(\mathrm{OBu})_{4}$ and $0.5 \mathrm{~mL}$ of ethyl acetate mixed with $23 \mathrm{~mL}$ of ethanol added. The mixture of this quasi- $\mathrm{TiO}_{2}$ nanoparticle was stirred continuously at $800 \mathrm{rpm}$ for $12 \mathrm{~h}$ and aged for $10 \mathrm{~h}$ at room temperature.

\subsection{Growth and Smooth Transfer of Graphene Films. Gra-} phene sheet growth is executed on a copper catalytic substrate in a thermal reactor at a temperature of $850^{\circ} \mathrm{C}$ via the plasma-enhanced chemical vapor deposition (PECVD) method [31]. The reaction uses a mixture of $\mathrm{CH}_{4}(20 \mathrm{sccm})$ and $\mathrm{H}_{2}(40 \mathrm{sccm})$ where $\mathrm{CH}_{4}$ and $\mathrm{H}_{2}$ act as the carbon source and the reduction gas, respectively. Graphene sheets on copper foil were then transferred to a silicon substrate by a wet transfer process with cyclododecane and cyclohexane. A 1:1 mixture of cyclododecane and cyclohexane was spincoated onto the surface of the copper/graphene film at $3000 \mathrm{rpm}$ for $30 \mathrm{~s}$. A pale white solid film was observed indicating the formation of a copper/graphene/cyclododecane film. The copper substrate on the back of the graphene was then completely dissolved after four hours by a $\mathrm{Cu}$ etchant, consisting of $\mathrm{FeCl}_{3}, \mathrm{HCl}$, and DI water. The clean graphene film was obtained after rinsing with deionized water for 3 times.

2.3. Fabrication of Photovoltaic Devices. An n-type singlecrystalline silicon $\langle 100\rangle$ thin bare wafer doped with phosphorous was purchased from Hefei Crystal Material Technology Co. Ltd. Silicon wafer has a resistivity of $1-5 \Omega / \mathrm{cm}$ and a thickness of $500 \mu \mathrm{m}$ for the substrate. The silicon wafer was first washed by acetone, ethanol solutions, and deionized water consecutively cleaning for $15 \mathrm{~min}$, respectively, under ultrasonic condition. The wafer was then dried by nitrogen gas. The gold electrode was sputtered on the top of the $\mathrm{SiO}_{2} / \mathrm{Si}$ substrate via the magnetron sputtering technique. To preserve the light absorption window, an area with a size of $3 \times 3 \mathrm{~mm}^{2}$ was masked in the middle of the $\mathrm{SiO}_{2} / \mathrm{Si}$ substrate. A $5 \% \mathrm{HF}$ solution was used to etch the oxide layer at room temperature for 3-5 min. Residual $\mathrm{HF}$ solution was washed off by deionized water for $5 \mathrm{~min}$ before the spin-coating GOQDs solution onto the $3 \times 3 \mathrm{~mm}^{2}$ window. The spin-coating speed is $1000 \mathrm{rpm}$ (representative thickness is $\sim 40 \mathrm{~nm}$ ), $3000 \mathrm{rpm}$ (representative thickness is $\sim 26 \mathrm{~nm}$ ), and $4000 \mathrm{rpm}$ (representative thickness is $\sim 12 \mathrm{~nm}$ ), respectively, and the spin-coating time is locked for the $30 \mathrm{~s}$ [13]. An annealing treatment at $200^{\circ} \mathrm{C}$ for $20 \mathrm{~min}$ after both processes for transferring of graphene and spin-coating with GOQDs. A rear electrode with the Ohmic contact on the back of the device is In-Ga alloy, and the device is placed at ethanol vapor for $3-5 \mathrm{~h}$ to clean the surface. A nano- $\mathrm{TiO}_{2}$ colloid solution for forming an antireflection layer trapped photons well-distributed and with $40-80 \mathrm{~nm}$ thickness is further spin-coated the top of the solar cell under $6000 \mathrm{rpm}$ for $1 \mathrm{~min}[13,28]$. Doping of graphene had been executed by placing the graphene side above the vapor of concentrated $\mathrm{HNO}_{3}$ for several times. This fabrication process is illustrated in Figure 1. 


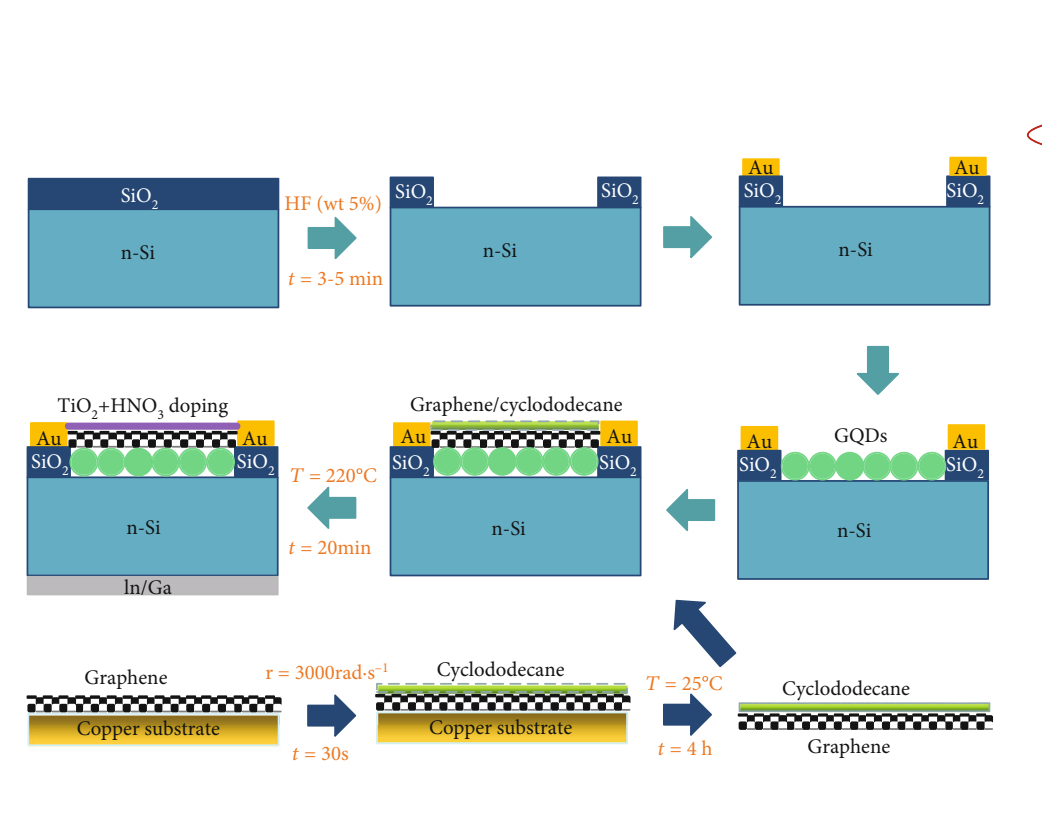

(a)

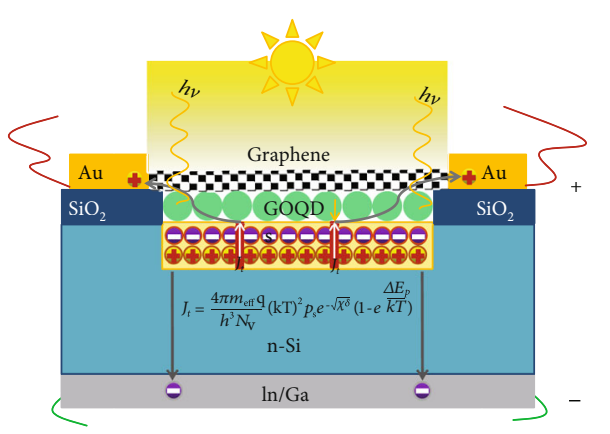

(b)

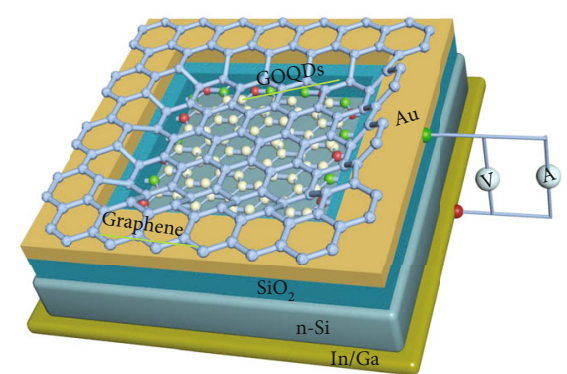

(c)

FIGURE 1: (a) Schematic illustration of the solar cell fabrication process. (b) Cross-sectional image shows both the electrons and holes are ripped out of the photo-generated electron-hole pairs at the interface under the driving force from the built-in electric field; then, the electrons invest in the silicon substrate while the electric field gives the holes access to the graphene electrode so that the device gets credit for converting from light energy to electric energy. (c) Schematic illustration of MIS Schottky junction solar cells with GOQD interlayer barrier.

2.4. Characterization of Device and Materials. The FourierTransform Infrared (FTIR) measurements were recorded from 4000 to $1000 \mathrm{~cm}^{-1}$ by an FTLA 2000 type spectrometer at a resolution of $4 \mathrm{~cm}^{-1}$ for 128 scans under room temperature. X-ray photoelectron spectroscopy (XPS, PHI-5000 $\mathrm{X}$-ray photoelectron spectrometer) was applied to analyze the chemical compositions of GOQDs films by an $\mathrm{Mg}$ $\mathrm{Ka}$ radiation source. The spectra of GOQDs were recorded from 0 to $1100 \mathrm{eV}$. Transmission Electron Microscopy (TEM) images of GOQDs were examined on a JEM-2100F Transmission Electron Microscope (JEOL, Japan). Fluorescence spectrometer (Ihr 320) and UV-vis spectrophotometer (UV-2550) were applied to gather photoluminescence (PL) and UV-vis spectra, respectively. Newport 91160 solar simulator with a $300 \mathrm{~W}$ xenon lamp and an AM 1.5G filter is used to simulate AM 1.5G solar irradiation. The solar simulator was calibrated by the silicon reference cell. To evaluate the performance for $\mathrm{Gr} / \mathrm{Si}$ SBSCs, the diode functions of the $J-V$ characteristics of SBSCs were measured under illuminated and in the dark conditions. Ideality $(n)$ and reverse saturation current $\left(J_{\text {sat }}\right)$ are calculated to analyze the diode functions by fitting the dark $J-V$ curve surveyed by the Agilent Probe analyzer as the following Eq. (1)

$$
J=J_{\text {sat }}\left[\mathrm{e}^{q V / n K T}-1\right]
$$

where $T$ is the absolute temperature, $K$ is the Boltzmann constant, $n$ is the ideality factor, $V$ is the applied voltage, $q$ is the unit charge, and $J$ is the current density [32].
The Schottky barrier height $\left(\phi_{B}\right)$ is affected by $J_{\text {sat }}$ and can be described by Eq. (2) [33].

$$
\varphi_{B}=-\mathrm{kT} \ln \left(\frac{J_{\mathrm{sat}}}{A^{*} T}\right),
$$

where $A *$ represents the effective Richardson constant $\left(\approx 112 \mathrm{~A} / \mathrm{cm}^{2}\right.$ for $\left.\mathrm{n}-\mathrm{Si}\right)$ [34].

\section{Results}

As a novel nanocarbon-based material, graphene oxide quantum dots (GOQDs) demonstrate typical characteristics of FTIR and XPS spectra as shown in Figure 2. For example, the FTIR spectrum (Figure 2(a)) reveals carboxyl and hydroxyl functional groups at 1644 and $3403 \mathrm{~cm}^{-1}$, respectively, and the XPS spectrum (Figure 2(b)) shows typical sp2 carbon peaks at 284.7, 286.1, and $287.9 \mathrm{eV}[13,30,35$, 36]. GOQDs inherit the unique properties from both graphene and quantum dots and are generally regarded as special graphene with a single- or few-layer and size of several nanometers [37]. These hydrophilic groups at the edge and on the surface of GOQDs sheets facilitate the alignment, the dispersion, and the stability of sheets in aqueous solution during the filtration and cleaning process. This is beneficial to enhance the physical contact of the graphene-GOQDs-silicon interface.

$J$ - $V$ characteristic curves of graphene/silicon-based Schottky heterojunction measured by experiment both in the dark and under illuminated conditions are shown in the right chart of Figure 3(a). The $J-V$ curve exhibited good 


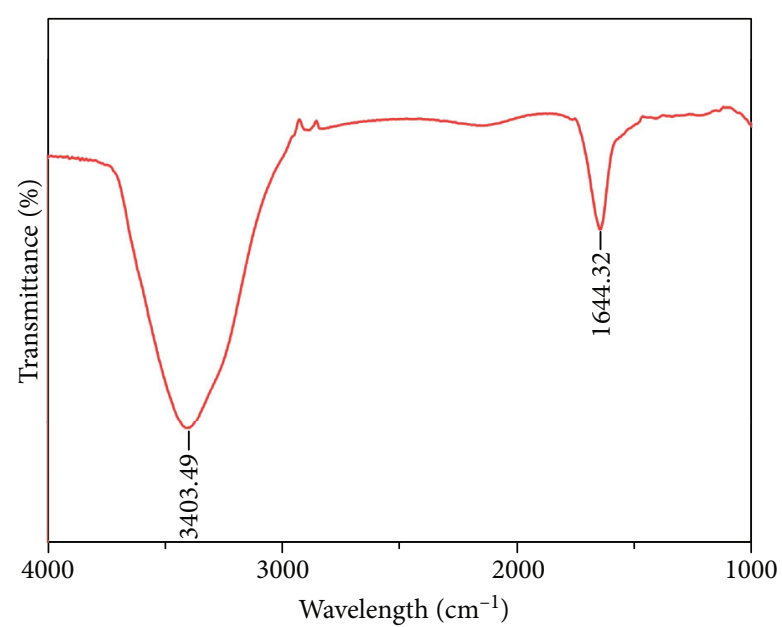

(a)

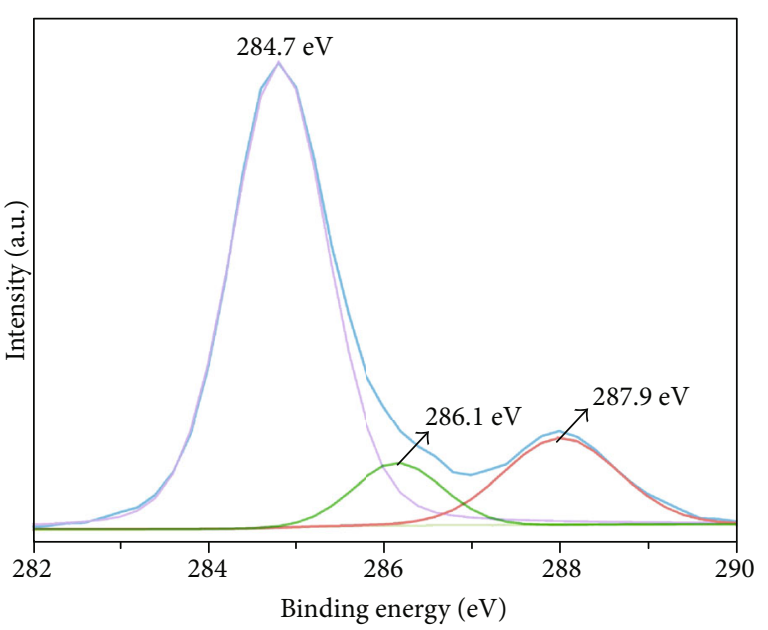

(b)

FIgURe 2: (a) FT-IR spectrum of GOQDs; (b) XPS survey spectra of GOQDs.

properties of nonlinear optical rectification in grapheneGOQDs-silicon coupling solar cells. The result is consistent with the previous studies of graphene and silicon Schottky junction $[38,39]$. To better illustrate the role of interfacial GOQDs interlayer, the energy band diagrams are shown in the left and middle charts in Figure 3(a). When the electron-hole pairs are generated, the built-in electric field $\left(V_{\mathrm{bi}}\right)$ at the silicon-graphene interface separates the charges and pulls the holes toward the graphene. The hole current density drew by graphene could be expressed as [40].

$$
J_{p}=\frac{q D_{p}}{L_{p}} p^{\prime}
$$

where $p^{\prime}$ represents the redundancy holes concentration in the silicon substrate under illumination, $L_{p}$ is the hole diffusion length, and $D_{p}$ is the characteristic diffusion coefficient for holes. These photo-generated holes must be consumed either by recombining with electrons or tunneling through a GOQDs barrier. The hole current density tunnelled from a GOQDs barrier has an available purpose for photocurrent and can be written as [41].

$$
J_{h}=\frac{4 \pi m_{\mathrm{eff}} q}{h^{3} N_{v}}(\mathrm{kT})^{2} p_{s} e^{-\sqrt{x} \delta}\left(1-e^{-\left(\Delta E_{p} / \mathrm{kT}\right)}\right)
$$

where $m_{\text {eff }}$ represents the hole effective mass, $N_{v}$ is the effective state density in the silicon substrate valence band, $p_{s}$ is the hole density at the interface, $\chi$ is the mean barrier height, $\delta$ is the GOQDs barrier thickness, and $\Delta E_{p}$ is the energy difference between the holes' quasi-Fermi level in the substrate under illumination and the graphene's Fermi level. The hole density $p_{s}$ is a function of $\Delta E_{p}$ as follows

$$
p_{s}=p_{\mathrm{s} 0} e^{\Delta E_{p} / \mathrm{kT}},
$$

where $p_{\mathrm{s} 0}$ represents the equilibrium concentration for holes at the interface in $\mathrm{Gr} / \mathrm{Si}$ SBSCs. It is obvious that the rising or falling in $p_{\mathrm{s} 0}$ is consistent with in the energy gap $\Delta E_{p}$ (detailed in energy band diagrams). In the absence of an interfacial barrier such as GOQDs, the electrons could recombine with holes freely at the silicon-graphene interface, and such pairs from the graphene side would have a much shorter lifetime (picoseconds) [42] so that do little to the photocurrent. On the other hand, if a large number of photo-generated holes would accumulate in the proximity of the GOQDs-silicon interface, the recombination of electrons with holes at the interface would have an adverse effect on the photocurrent. Assuming the Shockley-Read-Hall model, the surplus hole recombination rate in the wake of illumination can be expressed as [43].

$$
R_{T}=\frac{n_{s} p_{s}-n_{i}^{2}}{\tau_{\mathrm{h} 0}\left(n_{s}+n_{1}\right)+\tau_{\mathrm{e} 0}\left(p_{s}+p_{1}\right)} \approx \frac{n_{s} p_{s}-n_{i}^{2}}{\tau\left(n_{s}+p_{s}\right)},
$$

where $n_{1}=N_{c} e^{\left(E_{t}-E_{c}\right) / \mathrm{kT}}$ and $p_{1}=N_{v} e^{\left(E_{v}-E_{t}\right) / \mathrm{kT}}$ are associated with the energy level of the defect modes, $N_{c}$ is the effective state density in the silicon substrate conduction band, $E_{t}$ is the energy level of the defect modes, $n_{s}$ is the electron density at the interface, and $n_{i}$ is the intrinsic carrier concentration. It is further assumed that the time constant of electrons is approximately equal to that of the holes, and $E_{t}$ is close to the middle of the substrate band gap so that $n_{1}+p_{1}<<n_{\mathrm{s}}+$ $p_{s}$. Equation (6) assumes that the net recombination only occurs if $n_{s} p_{s}$ is larger than the intrinsic carrier product $n_{i}^{2}$ $\left(n_{s} p_{s}>n_{i}^{2}\right)$, and recombination is limited by whichever less of the carrier (holes or electrons). One can easily conclude that the tunneling current will increase if the surface hole concentration increases, while the recombination current would also rise as the product of $n_{s} p_{s}$ increases. Eventually, an equilibrium would be established that the sum of the recombination current $\left(J_{r}\right)$ and the tunneling current $\left(J_{t}\right)$ should equal to photocurrent $\left(J_{p}\right)$.

The above-mentioned analysis paves the way for explaining qualitatively the $J-V$ characteristic curve both 

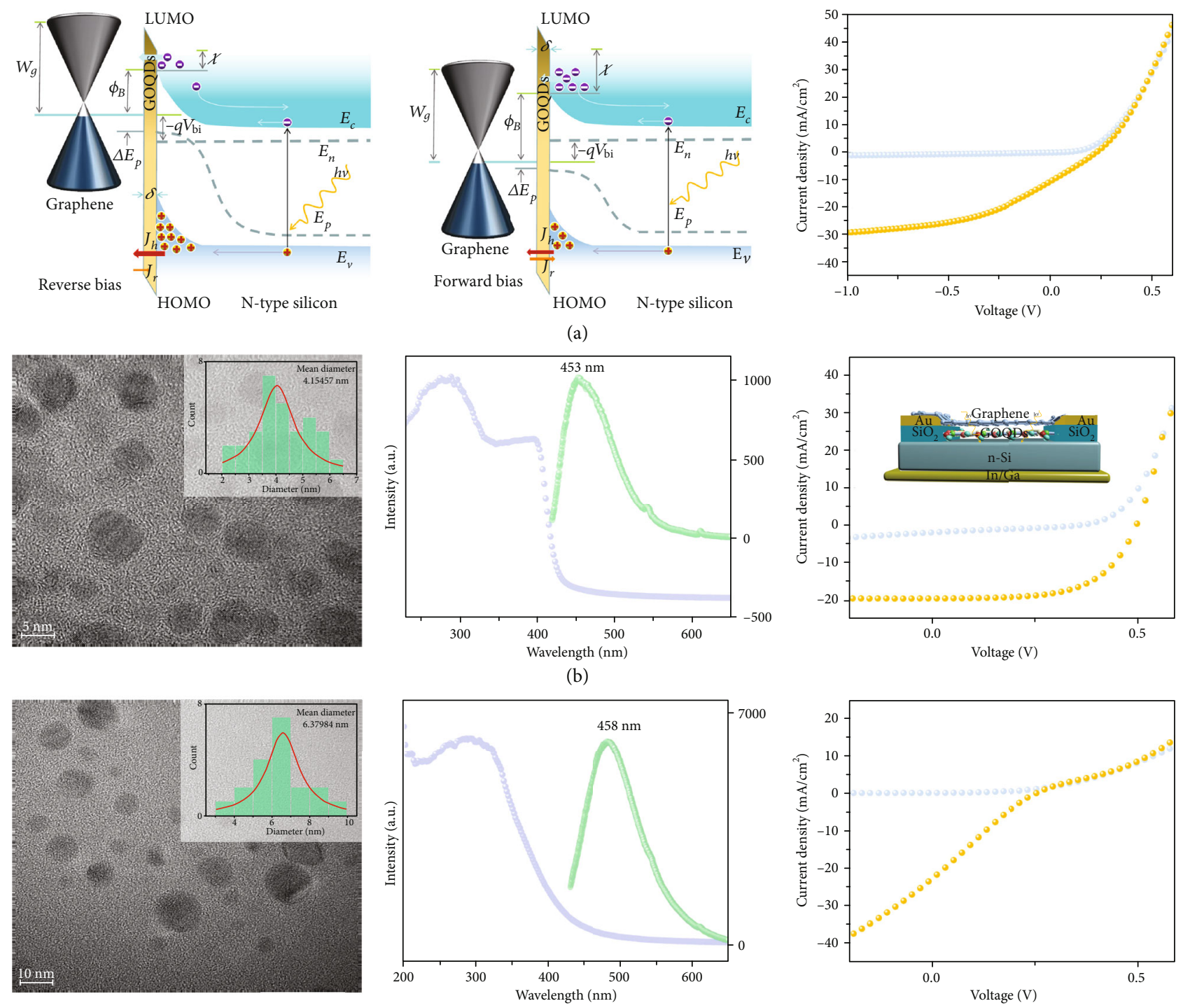

(c)

FIGURE 3: (a) Energy band diagrams of graphene-silicon Schottky heterojunction with GOQD interfacial barrier (left and middle chart) and the $J-V$ characteristics measured by experiment (right chart) for each case both under illuminated and in the dark conditions. (b) TEM image of GOQDs with a mean size of $4.15 \mathrm{~nm}$ with an insert of the size distribution of GOQDs (left chart), PL and UV-Vis spectrum (middle chart), and $J-V$ characteristic curve measured (right chart). (c) TEM image of GOQDs with a mean size of $6.38 \mathrm{~nm}$ with the insert of the size distribution of GOQDs (left chart), PL and UV-Vis spectrum (middle chart), and $J$ - $V$ characteristic curve (right chart).

under the illuminated or the dark conditions (shown the right chart in Figure 3) with GOQDs at $4.15 \mathrm{~nm}$ (Figure 3(b)) and $6.38 \mathrm{~nm}$ (Figure 3(c)). One can see that the Gr/GOQDs/Si SBSCs have a very small reverse current in the dark while increased significantly under illuminating. The photocurrent at zero bias is roughly equal to the reverse currents for devices, which suggest that there has a very low recombination rate of carriers at the interface in Gr/Si-based SBSCs [44]. In the reverse bias mode (the left chart in Figure 3(a)), the concentration of electrons at the interface is low owing to band-bending while a surplus of holes $p_{s}^{\prime}=p_{s}-p_{s 0}$ exists near the interface. $\Delta E_{p}$ and $p_{s}$ become large. As such, Eq. (5) demonstrated that the tunneling current becomes the dominant component for the photocurrent. In the case of weak forward biases (the middle chart in Figure 3(a)), the electron concentration at the interface will increase, and the recombination rate with holes is generally limited by the holes as the concentration $p_{s}^{\prime}$ for surplus holes decline. The results showed that the reverse saturation current without GOQDs is 20-fold or more than the $J_{\text {sat }}$ for with GOQDs barrier $(6.38 \mathrm{~nm}$ for particle size, Table S2).

The middle chart of photoluminescence (PL) spectra in Figures 3(b) and 3(c) showed a shift of peak from $453 \mathrm{~nm}$ 
TABle 1: Performance parameters of several devices with different GOQD sizes under AM1.5 Illumination.

\begin{tabular}{lcccc}
\hline GOQDs & $V_{\text {oc }}(\mathrm{V})$ & $J_{\text {sc }}\left(\mathrm{mA} / \mathrm{cm}^{2}\right)$ & Fill factor $(\%)$ & Efficiency $(\%)$ \\
\hline Without & 0.23 & 28.12 & 19.96 & 1.30 \\
$4.15 \mathrm{~nm}$ & 0.47 & 19.01 & 74.07 & 6.75 \\
$6.38 \mathrm{~nm}$ & 0.41 & 29.31 & 27.93 & 3.42 \\
\hline
\end{tabular}

TABle 2: Performance parameters of several Gr/GOQDs/Si SBSCs with different GOQD thickness under AM1.5 Illumination.

\begin{tabular}{lcccc}
\hline GOQDs & $V_{\text {oc }}(\mathrm{V})$ & $J_{\mathrm{sc}}\left(\mathrm{mA} / \mathrm{cm}^{2}\right)$ & Fill factor (\%) & Efficiency (\%) \\
\hline $12 \mathrm{~nm}$ & 0.37 & 38.95 & 32.30 & 4.65 \\
$26 \mathrm{~nm}$ & 0.47 & 19.01 & 74.07 & 6.75 \\
$40 \mathrm{~nm}$ & 0.43 & 14.41 & 26.58 & 1.68 \\
\hline
\end{tabular}

for GOQDs with a size of $4.15 \mathrm{~nm}$ to $458 \mathrm{~nm}$ for GOQDs with a size of $6.38 \mathrm{~nm}$. Such a blue shift is probably due to a larger gap in LUMO-HOMO, from $3.01 \mathrm{eV}$ to $3.36 \mathrm{eV}$ [13], when the particle size of GOQDs decreases from $6.38 \mathrm{~nm}$ to $4.15 \mathrm{~nm}$. The PCE showed an increase in the aggregate efficiency of $\mathrm{Gr} / \mathrm{Si}$-based SBSCs from $3.42 \%$ to $6.75 \%$ (Table 1). One can contribute to the overall efficiency of $6.75 \%$ as a result of regulating particle size as well as thickness for GOQDs (Table 2). According to Eq. (4), the hole tunneling current slips exponentially on account of the falling in a term $\mathrm{e}^{-\sqrt{\chi} \delta}$ as barrier thickness goes right. The rational thickness of the GOQDs interlayer in the interface of Gr/GOQDs/Si SBSCs should have the best tunneling effect as shown in Figure 4, evidenced by the lowest $J_{\text {sat }}$ of $8.14 \times$ $10^{-9} \mathrm{~A} / \mathrm{cm}^{2}$ (Table S3). The relative magnitudes of recombination current $J_{r}$ and photocurrent $J_{p}$ are represented by the size and the direction of the arrows in Figure 4. To illustrate, the relative abundance of holes and electrons in each case in Figure 4 is represented by the number of circles filled by a positive and negative sign. The influence of widening in thickness at the interface has appeared to the accompaniment of accumulating for holes near the silicon side which waiting to tunnel through but cannot (Figure 4). With a thin GOQDs interlayer barrier (say, $12 \mathrm{~nm}$ ) between the graphene and silicon, many holes are intrigued by graphene while the recombination of many electrons is simultaneously a drag on the photocurrent. With the GOQDs' thickness increases (to $26 \mathrm{~nm}$ ), $J_{\text {sat }}$ in the device decreases from $2.19 \times 10^{-8} \mathrm{~A} / \mathrm{cm}^{2}$ to $8.14 \times 10^{-9} \mathrm{~A} / \mathrm{cm}^{2}$, indirectly indicating that carrier recombination has been effectively suppressed. With the further increase of the GOQDs' thickness (to $40 \mathrm{~nm}$ ), the carrier recombination process is enhanced by about 20 times. In this case, the suppression of photocurrent in devices has also been implemented as the great quantity of holes piled up, proved by growth in $J_{\text {sat }}$ increase from $8.14 \times 10^{-9} \mathrm{~A} / \mathrm{cm}^{2}$ to $1.57 \times 10^{-7} \mathrm{~A} / \mathrm{cm}^{2}$.

Noting that a restriction of the range from 15 to $25 \AA$ has produced for the optimal insulation layer thickness in general MIS devices $[45,46]$, but why gets the ideal GOQDs barrier in this study come into $26 \mathrm{~nm}$ (Table 2)? We believe that three main behaviors exist in the Gr-GOQDs-Si interface: (1) light absorption of GOQDs film, (2) possible hole transport modes, and (3) GOQDs size-induced band bending. GOQDs interlayer has a capability for light absorbing to some extent then providing electron-hole pairs. The pair spring from the GOQDs layer serves to improve photocurrent thus growing the rational thickness of the GOQDs interlayer to some degree. As far as hole transports through GOQDs from silicon to graphene in Gr/GOQDs/Si SBSCs are concerned, the energy transfer process described by FÖrster Resonance Energy Transfer (FRET) should also be put on the agenda though the tunneling effect is dominant. The available of the effective energy transfer has performed under FRET as the GOQDs are close enough to graphene $(<10 \mathrm{~nm})$, indicating GOQDs contribute to hole transport then ameliorated the optimal thickness of the GOQDs barrier. On the other hand, there is a weak band bending between the GOQDs particles in the barrier, and this band bending has expanded with the rise of the size of GOQDs particles (supporting information). In addition, size-induced band bending may also occur between the GOQDs-Si interfaces. In the Gr/GOQDs/Si SBSCs, it can be considered that the LUMO value and HOMO value of Si substrate hardly change, which are $4.05 \mathrm{eV}$ and $5.17 \mathrm{eV}$, respectively. However, the corresponding values of GOQDs films have a strong sizedependent effect. For example, the LUMO values and $\mathrm{HOMO}$ values are $2.27 \mathrm{eV}$ and $5.28 \mathrm{eV}$ for size $6.38 \mathrm{~nm}$, while $1.99 \mathrm{eV}$ and $5.35 \mathrm{eV}$ for size $4.15 \mathrm{~nm}$ [13]. Extracting information to the aspect of band bending in Figure 3(a) to testify to the influential effect of GOQDs size-induced band bending in devices. The capability in the tunneling process for holes has been advanced since a reduction of curvature radius in the energy band (shown in the left in Figure 3(a)). An enhanced tunneling process as well as the energy transfer process brings a thick rational barrier (say, $26 \mathrm{~nm}$ ) for hole transporting. Combining the effects of GOQDs barrier on electrons and holes in Gr/Si-based SBSCs, the dual influences of GOQDs interlayer as an electron blocking and hole transport barrier are evident.

As one can see an S-shape distinctively revealed from the measured $J-V$ curves under illumination in both Figures 3 and 4 . Such shape corresponds to the waxing and waning of the interface and is commonly known to impede the performance of $\mathrm{Gr} / \mathrm{Si}$-based SBSCs. Hence, a relatively low $J_{\mathrm{sc}}$ with $19.01 \mathrm{~mA} / \mathrm{cm}^{2}$ in device with an efficiency of $6.57 \%$ has been deduced, and a high fill factor with 0.74 was estimated (Table 2 and Figures 5(c) and 5(d)). Studies showed that the interfacial barrier with thickness over $15 \AA$ generally induces the $S$-shape in $J-V$ curves $[9,11]$. Interestingly, in this study, we demonstrated an expanded capacity with a thick GOQDs barrier of $26 \mathrm{~nm}$, even thicker than the $20 \mathrm{~nm}$ layer thickness reported by Diao et al. [12]. The difference between the voltage of the experimentally observed value and the calculated value with the MIS model is only $0.09 \mathrm{~V}$ with the GOQDs thickness of $26 \mathrm{~nm}$. The MIS model can estimate the open-voltage of devices using both ideality $(n)$ and Schottky barrier height $\left(\phi_{B}\right)$ (Figure 5(a)). One can see the opposite influence of $\phi_{B}$ and $n$ on Gr/GOQDs/Si SBSCs 

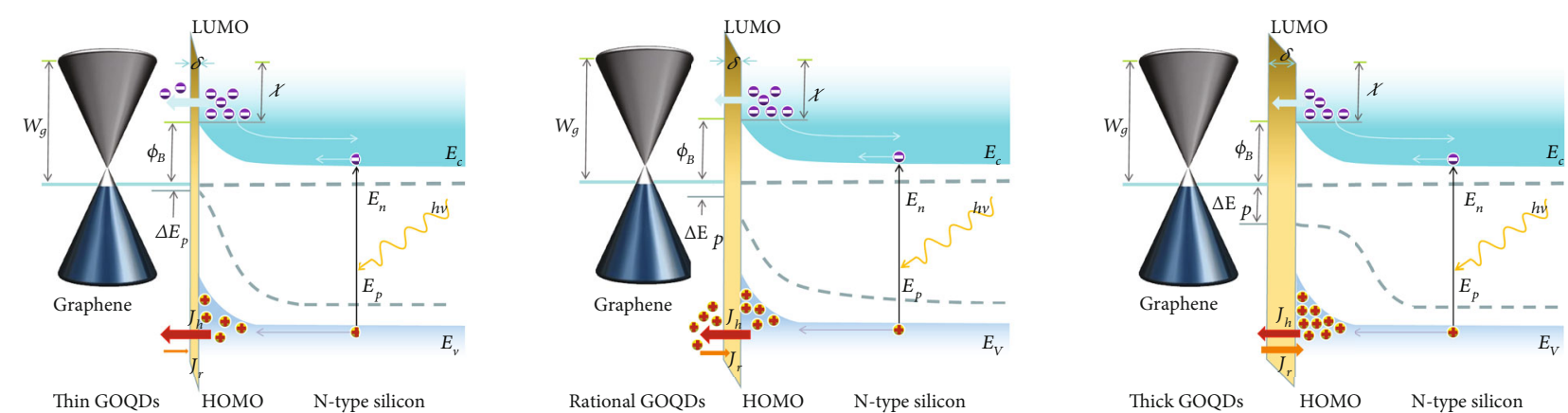

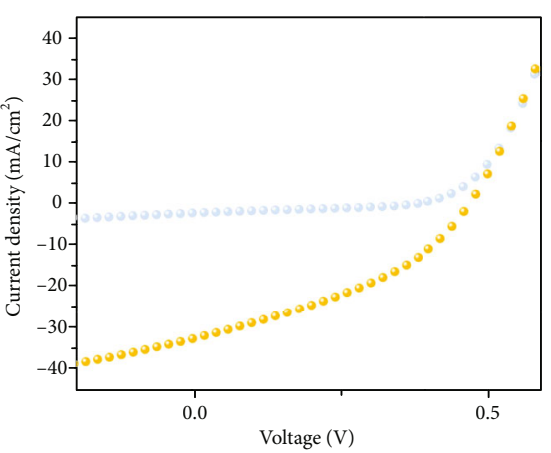

(a)

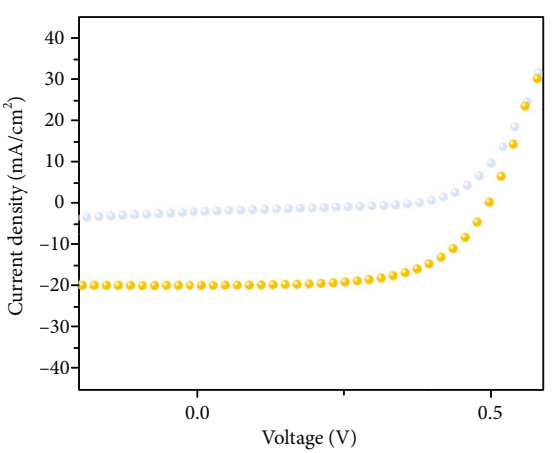

(b)

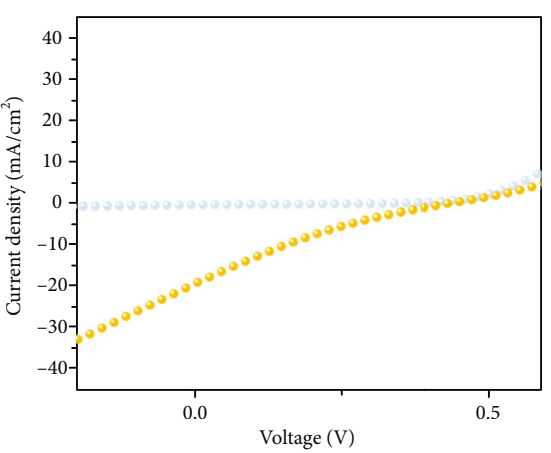

(c)

FIGURE 4: The schematic energy band diagrams of a graphene-silicon MIS Schottky junction with increasing GOQD interlayer barrier thickness (a) $12 \mathrm{~nm}$, (b) $26 \mathrm{~nm}$, and (c) $40 \mathrm{~nm}$, and the relative abundance of holes and electrons in each case is represented by the number of circles filled by a positive and negative sign. The corresponding $J-V$ characteristic curve measured by the experiment is shown below.

in open-voltage converge on the thickness of $26 \mathrm{~nm}$ where the $\phi_{B}$ favors the thickness less than $26 \mathrm{~nm}$ and $n$ favors thickness exceeds $26 \mathrm{~nm}$ (Figure 5(b)).

On the other hand, the light absorption capacity up to $30-40 \%$ within the visible range has been lost by the planar silicon. To reduce the reflectance, the antireflection coating (ARC) of $\mathrm{TiO}_{2}$ colloidal in $\mathrm{Gr} / \mathrm{Si}$-based SBSCs has been applied (Fig. S4). Compared with other materials, $\mathrm{TiO}_{2}$ has the advantages of large bandgap, unique refractive index, and easy processing into thin uniform layers. And its spin-coating has a strong antireflection effect on the condition of suitable film thickness and refractive index [28]. The refractive index $\left(n_{\mathrm{TiO}_{2}} \approx 2.2\right)$ of $\mathrm{TiO}_{2}$ colloid is between $\mathrm{Si}\left(n_{\mathrm{Si}} \approx 4\right)$ and air $\left(n_{\text {air }} \approx 1\right)$, which is approximately related to $n_{\mathrm{TiO}_{2}}=\sqrt{n_{\mathrm{Si}} n_{\text {air }}}$ [47]. Compared with the microcavity or photonic crystal, the visible transparent $\mathrm{TiO}_{2}$ colloid only acts as a planar antireflection layer, which suppresses the reflected light from polished silicon surface by destructive interference $[28,48]$. According to Tables 1 and 2, the best combination for Gr/GOQDs/Si SBSCs is $\sim 26 \mathrm{~nm}$ GOQDs thickness with a particle size of $4.15 \mathrm{~nm}$. After adding the ARC of $\mathrm{TiO}_{2}$ nanoparticles on the aforementioned device, a slight increase of PCE efficiency from $6.75 \%$ to $9.31 \%$ while the fill factor decreases from 0.74 to 0.67 (Table S4). However, both $V_{\text {oc }}$ and $J_{\text {sc }}$ increase from $0.47 \mathrm{~V}$ to $0.51 \mathrm{~V}$ and $19.01 \mathrm{~mA} / \mathrm{cm}^{2}$ to $27.25 \mathrm{~mA} / \mathrm{cm}^{2}$, respectively. The spin-coating of the nano- $\mathrm{TiO}_{2}$ sheet has strength- ened the light-capturing capability in Gr/Si-based SBSCs. But at the same time, it also increases series resistance due to extra physical contact introduced, which in turn can be fed back by the fill factor. This explains an increase in $J_{\mathrm{sc}}$ from $19.01 \mathrm{~mA} / \mathrm{cm}^{2}$ to $27.25 \mathrm{~mA} / \mathrm{cm}^{2}$ and a decrease in fill factor from 0.74 to 0.67 . In addition, $\mathrm{TiO}_{2}$ might also lead to $\mathrm{p}$ type doping of graphene, therefore enhancing $V_{\mathrm{oc}}$ from $0.47 \mathrm{~V}$ to $0.51 \mathrm{~V}$, as discussed in the literature [49]. The results show that the PCE efficient increases after ARC treatment regardless of the thickness of the GOQDs barrier. For example, PCE increases from $1.68 \%$ to $3.66 \%$ with a thicker $\sim 40 \mathrm{~nm}$ GOQDs with an ARC, where $\sim 26 \mathrm{~nm}$ thickness of GOQDs barrier increases from $6.75 \%$ to $9.31 \%$. However, the $V_{\text {oc }}$ drops slightly with the thicker GOQDs layer $(40 \mathrm{~nm}$, from $0.43 \mathrm{~V}$ to $0.36 \mathrm{~V})$ while the thinner one increases slightly from 0.47 to $0.51 \mathrm{~V}$. The $J_{\text {sc }}$ with thick GOQDs layer goes up more than the thinner one, from $14.41 \mathrm{~mA} / \mathrm{cm}^{2}$ to $37.39 \mathrm{~mA} / \mathrm{cm}^{2}$, and fill factor boosts from 0.26 to 0.27 .

Studies demonstrated that doping graphene and carbon nanotubes with $\mathrm{HNO}_{3}$ can improve the graphene p-type conductivity [50-52]. We investigate the doping effect on the Gr/GOQDs/Si SBSCs (Table S5). The results are consistent with previous studies $[51,52]$. The PCE increases to $11.69 \%$ and $13.67 \%$ after $10 \mathrm{~s}$ and $15 \mathrm{~s}$. However, further doping at the $20 \mathrm{~s}$ does not increase the PCE, rather dropped to $10.71 \%$. The energy band diagrams further illustrate a 


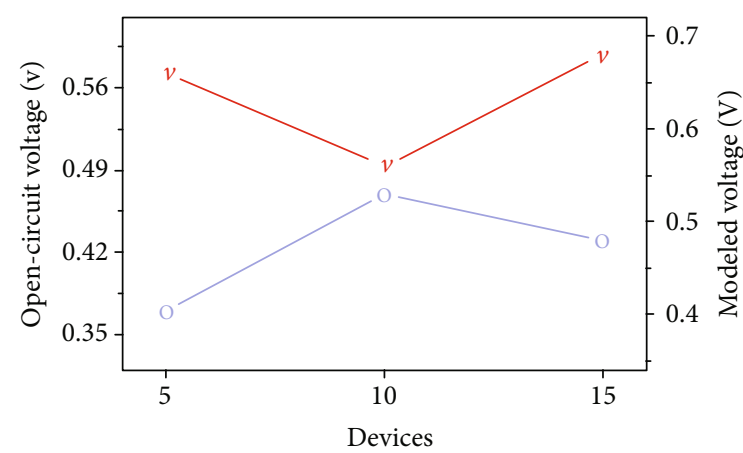

- 0 - Open-circuit voltage

$-v-$ Calculated by MIS model

(a)

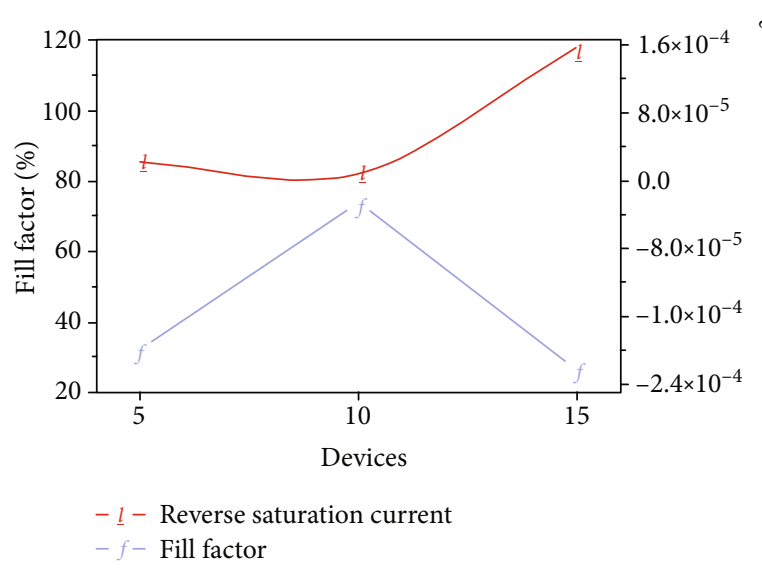

(c)

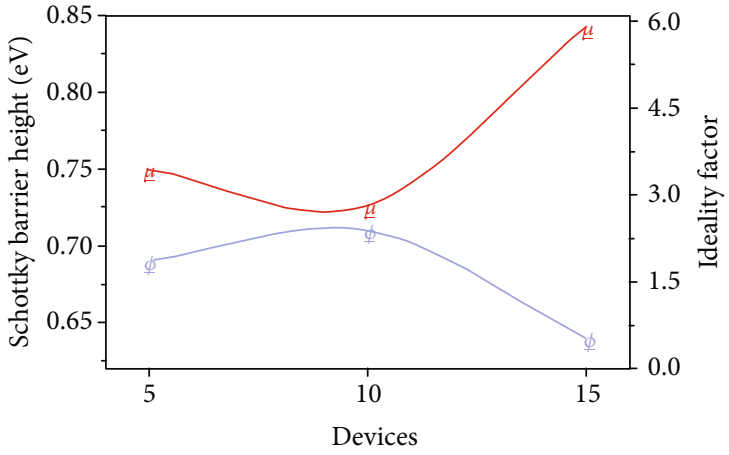

$-\phi-$ Schottky barrier height

- $\underline{-}$ - Ideality factor

(b)

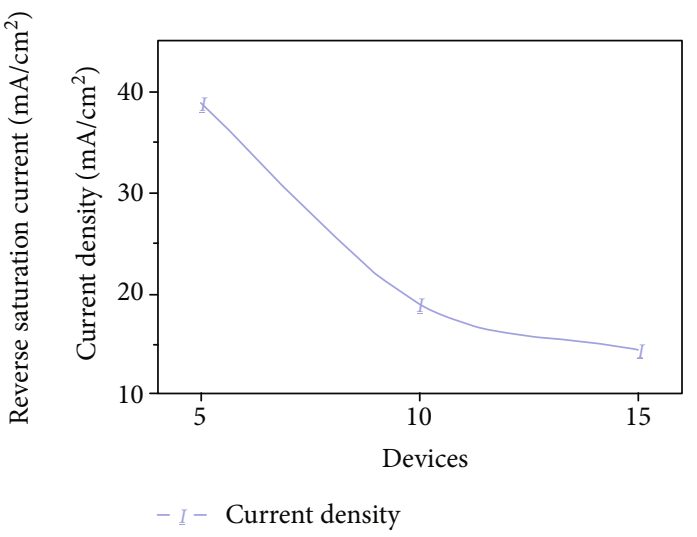

(d)

FIGURE 5: Extracted photovoltaic parameters for Gr/GOQDs/Si SBSCs: (a) $V_{\text {oc }}$ distribution of measured by experiment and calculated by MIS model; (b) distribution of ideal factor and Schottky barrier height; (c) distribution of fill factor and reverse saturation current, on the condition that the several thicknesses of GOQD interfacial barrier (device a is with $12 \mathrm{~nm}$ GOQDs, b with $26 \mathrm{~nm}$, and c with $40 \mathrm{~nm}$, respectively).

smaller curvature radius of energy band at GOQDs-Si interface in SBSCs with $\mathrm{HNO}_{3}$ doping (Figure S3). This induced an increase in $W_{g}$ because the equilibrium interfaces concentration of holes $p_{\mathrm{s} 0}$ increases while the electrons concentration $n_{\mathrm{s} 0}$ is decreasing. This will result in less-surplus carriers (namely, electrons), and recombination current will decrease for a given bias. The tunneling current of holes will increase at the other side of the shield as it is controlled by $p_{\mathrm{s}}$ (Eq. (4)). The increase of $p_{\mathrm{s} 0}$ will create a raise in $p_{\mathrm{s}}$ as described by Eq. (5). The intensification of the tunneling process at Gr-GOQDs-Si interface in Gr/GOQDs/Si SBSCs is consistent with the results observed by the experiment, which $J_{\mathrm{sc}}$ for device showed an increase from untreated $27.25 \mathrm{~mA} / \mathrm{cm}^{2}$ to $37.90 \mathrm{~mA} / \mathrm{cm}^{2}$; therefore, efficiency of $13.67 \%$ has ultimately achieved. From the $V_{\mathrm{oc}}$ of $0.50 \mathrm{~V}( \pm 30 \mathrm{mV})$ and an efficiency of $13.67 \%$, the Gr/GOQDs/Si SBSC creates the highest fill factor for 0.75 at the cost of left-shifted with $30 \mathrm{mV}$ or so in the measured $J$ $V$ characteristics curve under illumination. It is interesting to point out that the fill factor, $J_{\mathrm{sc}}$, and PCE efficiency all decreased from $0.75,37.90 \mathrm{~mA} / \mathrm{cm}^{2}$, and $13.67 \%$ to 0.66 , $31.96 \mathrm{~mA} / \mathrm{cm}^{2}$, and $10.71 \%$, respectively, when the doping treatment time increases to $20 \mathrm{~s}$ (Figure 6(b)). This phenomenon has also been observed in other solar cells which might be created both by the degradation of graphene film and the oxidization of the silicon substrate surface with the concentrated $\mathrm{HNO}_{3}[9,51,52]$. Compared to the solar cell with an efficiency of $15.60 \%$ reported by Song et al. [9], our devices have slightly lower $V_{\text {oc }}$ but higher $J_{\mathrm{sc}}$ and fill factor owing to the lower doping levels of the silicon substrate.

The stability of the solar cells during the storage of $\mathrm{Gr} / \mathrm{Si}$ based SBSCs after doping treatment has also been studied through the device with both optimal measurements of the $J_{\text {sc }}$ and $V_{\text {oc }}$, corresponding to a better tunneling effect. A set of photovoltaic performance data of the device stored in air for 60 days without any encapsulation were measured every ten days. Figure 7 illustrates the parameters of the device with respect to the storing time. It is obvious that the Gr/GOQDs/Si-based SBSCs still perform well after 60 days, and the stability of the device is maintained as four performance parameters (fill factor, PCE, open-circuit voltage, and current density) show little change. For example, the PCE efficiency dropped from $11.69 \%$ to $10.56 \%$ after 60 days, 


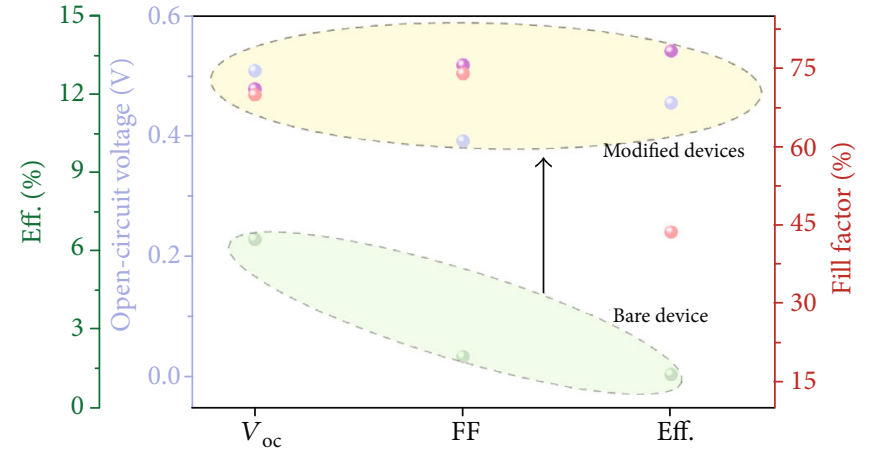

(a)

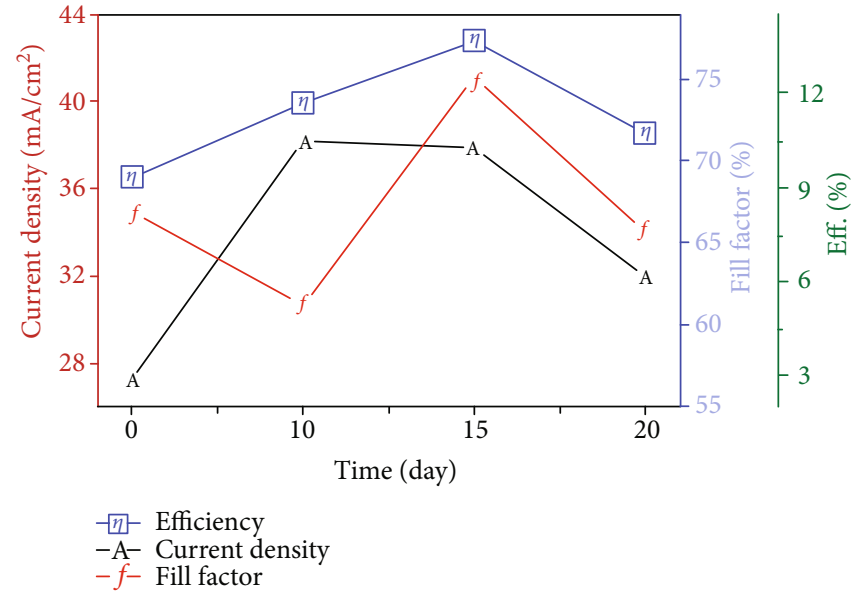

(b)

FIgURE 6: Extracted photovoltaic parameters: (a) distribution of $V_{o c}$, fill factor, and efficiency, respectively, for parallel Gr/Si-based SBSCs with several treatments; (b) distribution of $J_{s c}$, fill factor, and efficiency, respectively, for parallel Gr/Si-based SBSCs with several doping times.

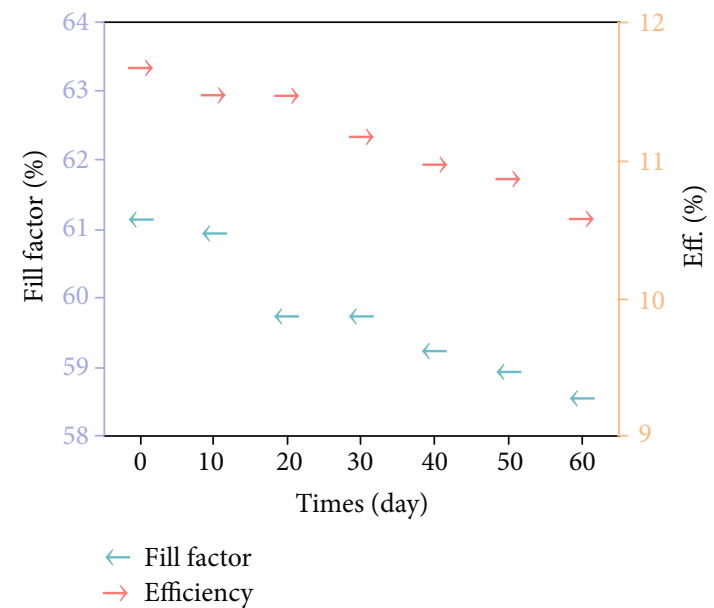

(a)

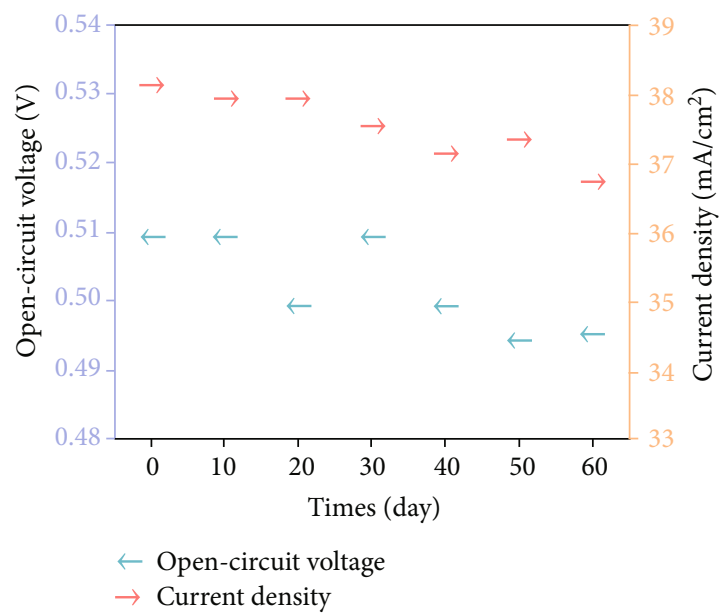

(b)

Figure 7: Stability characteristics with efficiency and fill factor (a) and $V_{\text {oc }}$ and $J_{\text {sc }}$ (b) for Gr/Si-based SBSCs after doping treatment.

fill factor abated from $61.2 \%$ to $58.6 \%, V_{\text {oc }}$ weaken from $0.51 \mathrm{~V}$ to $0.496 \mathrm{~V}$, and $J_{\mathrm{sc}}$ descended from $38.20 \mathrm{~mA} / \mathrm{cm}^{2}$ to $36.82 \mathrm{~mA} / \mathrm{cm}^{2}$, respectively. Besides the excellent stability of graphene and GOQDs, the nano- $\mathrm{TiO}_{2}$ antireflective coating layer on the top of the device also contributes to its stability by reducing the oxidation rate of the silicon-based substrate. It is expected that the durability of solar cells could be further enhanced by employing more stable preservation methods.

\section{Discussion}

In summary, the unique quantum effect of GOQDs is a novel nanomaterial that can modify the interface in Gr/Si SBSCs and serve as a distinctive barrier at the interface. The holes tunneling process and the carriers' recombination rate can be controlled by the thickness and particle size for GOQDs barrier in the Gr/Si SBSCs. The extra band bending induced by GOQDs in Gr/Si-based SBSCs provides a mechanism for the improved PCE. The combination of $4.15 \mathrm{~nm}$ particle size and $26 \mathrm{~nm}$ of GOQDs film thickness seems to be the optimal GOQDs profile in making an efficient $\mathrm{Gr} / \mathrm{Si}$ SBSCs. In addition, both the ARC of device and doping on GOQDs brought the overall PCE of Gr/Si-based SBSC to $13.67 \%$ along with the good stability in air. However, prolong doping time with $\mathrm{HNO}_{3}$ does not provide further PCE improvement due to the degradation of graphene and oxidation of silicon substrate. This $26 \mathrm{~nm}$ thickness of GOQDs would be easier to manufacture than the existing barrier thickness. This would be a cost-effective design and provide a wider application.

\section{Data Availability}

All data, models, or code generated or used during the study are available from the first author or corresponding author by request. (Chao Geng, Email: qdsslmq@126.com). 


\section{Conflicts of Interest}

The authors declare that they have no known competing financial interests.

\section{Acknowledgments}

The financial support of this work is from the National Natural Science Foundation of China (Grant No. 61764009, 51762043, 51974143), the National Key R\&D Program of China (No. 2018YFC1901801, No. 2018YFC1901805), the Major Science and Technology Projects in Yunnan Province (No. 2019ZE007), the Key Project of Yunnan Province Natural Science Fund (No. 2018FA027), the Yunan Ten Thousand Talents Plan Young \& Elite Talents Project, and the Program for Innovative Research Team in University of Ministry of Education of China (No. IRT_17R48).

\section{Supplementary Materials}

Table S1: measured discrete data for V and I. Table S2: performance parameters of several devices with different GOQD sizes under AM1.5 Illumination (measured) and in the dark conditions (calculated by it). Table S3: performance parameters of several Gr/GOQDs/Si SBSCs with different GOQD thickness under AM1.5 Illumination (measured) and in the dark conditions (calculated by it). Figure S1: dark $J-V$ curves for Gr/GOQDs/Si-based SBSCs before/after ARC and HNO3 treatment. Figure S2: plots of $\mathrm{dV} / \mathrm{d}(\ln J)$ vs. $J$ for $\mathrm{Gr} / \mathrm{GOQDs} / \mathrm{Si}$-based SBSCs before/after ARC and $\mathrm{HNO} 3$ treatment. Figure S3: EDS diagram of nano-TiO2 particles. Figure S4: TEM diagram of nano-TiO2 particles. Table S4: performance parameters of Gr/GOQDs/Si SBSCs before and after ARC treatment under AM1.5 Illumination. Table S5: performance parameters of Gr/GOQDs/Si SBSCs treated both by ARC and $\mathrm{HNO} 3$ doping under AM1.5 Illumination. Particle size-induced band bending. (Supplementary Materials)

\section{References}

[1] Global Energy Transformation: A Roadmap to 2050 (2019 edition)https://www.irena.org/publications/2019/Apr/Globalenergy-transformation-A-roadmap-to-2050-2019Edition.

[2] B. Chen, Z. Yu, K. Liu et al., "Grain engineering for perovskite/silicon monolithic tandem solar cells with efficiency of 25.4\%," Joule, vol. 3, no. 1, pp. 177-190, 2019.

[3] C. C. Chen, M. Aykol, C. C. Chang, A. F. J. Levi, and S. B. Cronin, "Graphene-silicon Schottky diodes," Nano Letters, vol. 11, no. 5, pp. 1863-1867, 2011.

[4] G. Luongo, A. Grillo, F. Urban, F. Giubileo, and A. D. Bartolomeo, "Effect of silicon doping on graphene/silicon Schottky photodiodes," Materials Today processing, vol. 20, pp. 82-86, 2020.

[5] S. K. Behura, C. Wang, Y. Wen, and V. Berry, "Graphenesemiconductor heterojunction sheds light on emerging photovoltaics," Nature Photonics, vol. 13, no. 5, pp. 312-318, 2019.
[6] L. Yang, W. Chen, Q. Yu, and B. Liu, "Mass production of two-dimensional materials beyond graphene and their applications," Nano Research, vol. 13, pp. 1-15, 2020.

[7] X. M. Li, H. W. Zhu, K. L. Wang et al., "Graphene-on-silicon Schottky junction solar cells," Advanced Materials, vol. 22, no. 25, pp. 2743-2748, 2010.

[8] X. Kong, L. Zhang, B. Liu et al., "Graphene/Si Schottky solar cells: a review of recent advances and prospects," RSC Advances, vol. 9, no. 2, pp. 863-877, 2019.

[9] Y. Song, X. Li, C. Mackin et al., "Role of interfacial oxide in high-efficiency graphene-silicon Schottky barrier solar cells," Nano Letters, vol. 15, no. 3, pp. 2104-2110, 2015.

[10] S. Yavuz, C. Kuru, D. Choi, A. Kargar, S. Jin, and P. R. Bandaru, "Graphene oxide as a p-dopant and an anti-reflection coating layer, in graphene/silicon solar cells," Nanoscale, vol. 8, no. 12, pp. 6473-6478, 2016.

[11] L. Yang, X. Yu, W. Hu, X. Wu, Y. Zhao, and D. Yang, “An $8.68 \%$ efficiency chemically-doped-free graphene-silicon solar cell using silver nanowires network buried contacts," ACS Applied Materials \& Interfaces, vol. 7, pp. 4135-4141, 2015.

[12] S. Diao, X. Zhang, Z. Shao, K. Ding, J. Jie, and X. Zhang, " $12.35 \%$ efficient graphene quantum dots/silicon heterojunction solar cells using graphene transparent electrode," Nano Energy, vol. 31, pp. 359-366, 2017.

[13] C. Geng, Y. Shang, J. Qiu et al., "Carbon quantum dots interfacial modifified graphene/silicon Schottky barrier solar cell," Journal of Alloys and Compounds, vol. 835, article 155268, 2020.

[14] X. Zhang, C. Xie, J. Jie, X. Zhang, Y. Wu, and W. Zhang, "Highefficiency graphene/Si nanoarray Schottky junction solar cells via surface modification and graphene doping," Journal of Materials Chemistry A, vol. 1, no. 22, pp. 6593-6601, 2013.

[15] M. Zhong, D. Xu, X. Yu, K. Huang, X. Liu, and Y. Qu, "Interface coupling in graphene/fluorographene heterostructure for high- performance graphene/silicon solar cells," Nano Energy, vol. 28, pp. 12-18, 2016.

[16] J. Meng, X. Liu, X. Zhang, Y. Zhang, and H. Wang, "Interface engineering for highly efficient graphene-on-silicon Schottky junction solar cells by introducing a hexagonal boron nitride interlayer," Nano Energy, vol. 28, pp. 44-50, 2016.

[17] C. Xie, X. Z. Zhang, Y. M. Wu et al., "Surface passivation and band engineering: a way toward high efficiency graphene-planar Si solar cells," Journal of Materials Chemistry A, vol. 1, no. 30, pp. 8567-8574, 2013.

[18] K. J. Jiao, X. L. Wang, Y. Wang, and Y. F. Chen, "Graphene oxide as an effective interfacial layer for enhanced graphene/silicon solar cell performance," Journal of Materials Chemistry C, vol. 2, no. 37, pp. 7715-7721, 2014.

[19] A. Wang, J. Zhao, and M. A. Green, " $24 \%$ efficient silicon solar cells," Applied Physics Letters, vol. 57, no. 6, pp. 602-604, 1990.

[20] J. H. Zhao, A. H. Wang, M. A. Green, and F. Ferrazza, " $19.8 \%$ efficient "honeycomb" textured multicrystalline and $24.4 \%$ monocrystalline silicon solar cells," Applied Physics Letters, vol. 73, no. 14, pp. 1991-1993, 1998.

[21] X. Miao, S. Tongay, M. K. Petterson et al., "High efficiency graphene solar cells by chemical doping," Nano Letters, vol. 12, no. 6, pp. 2745-2750, 2012.

[22] P. Ho, Y. Liou, C. Chuang et al., "Self-crack-filled graphene films by metallic nanoparticles for high-performance graphene heterojunction solar cells," Advanced Materials, vol. 10, pp. 1724-1729, 2015. 
[23] X. Liu, X. W. Zhang, J. H. Meng et al., "High efficiency Schottky junction solar cells by co-doping of graphene with gold nanoparticles and nitric acid," Applied Physics Letters, vol. 106, no. 23, article 233901, 2015.

[24] M. E. Ayhan, G. Kalita, and M. Tanemura, "Photoresponsivity of silver nanoparticles decorated graphene-silicon Schottky junction," RSC Advances, vol. 4, no. 51, pp. 26866-26871, 2014.

[25] K. Huang, Y. Yan, X. Yu, H. Zhang, and D. Yang, "Graphene coupled with Pt cubic nanoparticles for high performance, air-stable graphene-silicon solar cells," Nano Energy, vol. 32, pp. 225-231, 2017.

[26] X. Yu, L. Yang, Q. Lv, M. Xu, H. Chen, and D. Yang, "The enhanced efficiency of graphene-silicon solar cells by electric field doping," Nanoscale, vol. 7, no. 16, pp. 7072-7077, 2015.

[27] X. Li, D. Xie, H. Park, M. Zhu, and H. Zeng, "Ion doping of graphene for high-efficiency heterojunction solar cells," Nanoscale, vol. 5, no. 5, pp. 1945-1948, 2013.

[28] E. Z. Shi, H. B. Li, L. Yang et al., "Colloidal antireflection coating improves graphene-silicon solar cells," Nano Letters, vol. 13, no. 4, pp. 1776-1781, 2013.

[29] R. Hezel, "High-efficiency OECO Czochralski-silicon solar cells for mass production," Solar Energy Materials and Solar Cells, vol. 74, no. 1-4, pp. 25-33, 2002.

[30] C. Zhang, K. Wei, W. Zhang, Y. Bai, Y. Sun, and J. Gu, "Graphene oxide quantum dots incorporated into a thin film nanocomposite membrane with high flux and antifouling properties for low-pressure nanofiltration," ACS Applied Materials \& Interfaces, vol. 9, no. 12, pp. 11082-11094, 2017.

[31] T. Terasawa and K. Saiki, "Growth of graphene on $\mathrm{Cu}$ by plasma enhanced chemical vapor deposition," Carbon, vol. 50, no. 3, pp. 869-874, 2012.

[32] S. K. Cheung and N. W. Cheung, "Extraction of Schottky diode parameters from forward current-voltage characteristics," Applied Physics Letters, vol. 49, no. 2, pp. 85-87, 1986.

[33] H. He, X. Yu, Y. Wu et al., “13.7\% Efficiency graphene-gallium arsenide Schottky junction solar cells with a P3HT hole transport layer," Nano Energy, vol. 16, pp. 91-98, 2015.

[34] L. Yang, X. Yu, M. Xu, H. Chen, and D. Yang, "Interface engineering for efficient and stable chemical-doping-free graphene-on-silicon solar cells by introducing a graphene oxide interlayer," Journal of Materials Chemistry A, vol. 2, no. 40, pp. 16877-16883, 2014.

[35] Q. Mei, J. Chen, J. Zhao et al., “Atomic oxygen tailored graphene oxide nanosheets emissions for multicolor cellular imaging," ACS Applied Materials \& Interfaces, vol. 8, no. 11, pp. 7390-7395, 2016.

[36] L. Peng, Z. Xu, Z. Liu et al., "An iron-based green approach to 1-h production of single-layer graphene oxide," Nature Communications, vol. 6, no. 1, article 5716, 2015.

[37] S. Wang, Z. G. Chen, I. Cole, and Q. Li, "Structural evolution of graphene quantum dots during thermal decomposition of citric acid and the corresponding photoluminescence," Carbon, vol. 82, pp. 304-313, 2015.

[38] X. An, F. Liu, Y. J. Jung, and S. Kar, "Tunable graphene-silicon heterojunctions for ultrasensitive photodetection," Nano Letters, vol. 13, no. 3, pp. 909-916, 2013.

[39] P. Lv, X. Zhang, X. Zhang, W. Deng, and J. Jie, "High-sensitivity and fast-response graphene/crystalline silicon Schottky junction-based near-IR photodetectors," IEEE Electron Device Letters, vol. 34, no. 10, pp. 1337-1339, 2013.
[40] H. C. Card and E. Rhoderic, "Studies of tunnel MOS diodes I. Interface effects in silicon Schottky diodes," Journal of Physics D: Applied Physics, vol. 4, no. 10, pp. 1589-1601, 1971.

[41] K. K. Ng and H. C. Card, "Asymmetry in the $\mathrm{SiO}_{2}$ tunneling barriers to electrons and holes," Journal of Applied Physics, vol. 51, no. 4, pp. 2153-2157, 1980.

[42] T. Limmer, J. Feldmann, and D. E. Como, "Carrier lifetime in exfoliated few-layer graphene determined from intersubband optical transitions," Physical Review Letters, vol. 110, no. 21, article 217406, 2013.

[43] W. Shockley and W. T. Read, "Statistics of the recombinations of holes and electrons," Physics Review, vol. 87, no. 5, pp. 835842, 1952.

[44] L. H. Zeng, M. Z. Wang, H. Hu et al., "Monolayer graphene/germanium Schottky junction as high-performance self-driven infrared light photodetector," ACS Applied Materials \& Interfaces, vol. 5, no. 19, pp. 9362-9366, 2013.

[45] P. Viktorovitch, G. Pananakakis, G. Kamarinos, and R. Basset, "Determination of optimum parameters and characterization of MIS solar cells," in 1977 International Electron Devices Meeting, Washington, DC, USA, December 1977.

[46] K. K. Ng and H. C. Card, "Photocurrent suppression and interface state recombination in MIS-Schottky barriers," in 1977 International Electron Devices Meeting, pp. 57-61, Washington, DC, USA, December 1977.

[47] H. K. Raut, V. A. Ganesh, A. S. Nair, and S. Ramakrishna, "Anti-reflective coatings: a critical, in-depth review," Energy Environ Sciences, vol. 4, no. 10, pp. 3779-3804, 2011.

[48] E. Johannes, G. L. Benjamin, B. Jan et al., "Rear side sphere gratings for improved light trapping in crystalline silicon single junction and silicon-based tandem solar cells," Solar Energy Materials \& Solar Cells, vol. 142, pp. 60-65, 2015.

[49] A. Du, Y. H. Ng, N. J. Bell, Z. Zhu, R. Amal, and S. C. Smith, "Hybrid graphene/titania nanocomposite: interface charge transfer, hole doping, and sensitization for visible light response," Journal of Physical Chemistry Letters, vol. 2, no. 8, pp. 894-899, 2011.

[50] S. Bae, H. Kim, Y. Lee et al., "Roll-to-roll production of 30-inch graphene films for transparent electrodes," Nature Nanotechnology, vol. 5, no. 8, pp. 574-578, 2010.

[51] R. A. Nistor, D. M. Newns, and G. J. Martyna, "The role of chemistry in graphene doping for carbon-based electronics," ACS Nano, vol. 5, no. 4, pp. 3096-3103, 2011.

[52] A. Kasry, M. A. Kuroda, G. J. Martyna, G. S. Tulevski, and A. A. Bol, "Chemical doping of large-area stacked graphene films for use as transparent, conducting electrodes," ACS Nano, vol. 4, no. 7, pp. 3839-3844, 2010. 